\title{
A difficult case: Ectopic thyroid, bronchial anomalies, and incidentaloma in a patient with lung carcinoma
}

\author{
Salih Topcu, MD, ${ }^{\text {a }}$ Serife Tuba Liman, MD, ${ }^{\text {a }}$ Aykut Elicora, MD, ${ }^{\mathrm{a}}$ Ferzat Zanuzi, MD, \\ Serkan Isgoren, $\mathrm{MD},{ }^{\mathrm{b}}$ and Deniz Filinte, $\mathrm{MD},{ }^{\mathrm{c}}$ Kocaeli, Turkey
}

True primary mediastinal ectopic goiters are very rarely seen, accounting for fewer than $1 \%$ of all goiters. ${ }^{1}$ They originate from ectopic thyroid tissue located in the mediastinum, without any connection with the cervical thyroid gland. Here we discuss the case of a patient with a lung nodule and mediastinal mass with associated bronchial abnormality.

\section{CLINICAL SUMMARY}

Mediastinal enlargement and a solitary pulmonary nodule were detected on a 68-year-old male patient's chest radiograph during routine annual examination. Computed tomography and magnetic resonance imaging revealed a lobulated, solid, and well-demarcated right paratracheal mass $6 \times 4 \times$ $4 \mathrm{~cm}$ in dimension (Figure 1). The solitary, heterogeneous parenchymal mass located in the right upper lobe was $4 \times$ $3 \times 3 \mathrm{~cm}$ in dimension. Results of thyroid function tests were within reference range. Right tracheal bronchus (bronchus suis) was observed on bronchoscopy. Results of bronchoscopy and bronchial lavage cytologic examination were not diagnostic. Positron emission tomography (PET)-computed tomography revealed metabolic activity both in the parenchymal mass (standard uptake values 8.3 early and 9.6 late) and in the nodule of left thyroid lobe (standard uptake values 4.1 early and 5.1 late; Figure 1). There was no metabolic activity in the mediastinal mass or mediastinal lymph node stations. Computed tomographically guided transthoracic fine-needle aspiration of the parenchymal mass revealed non-small cell lung carcinoma. Thyroid ultrasonography and scintigraphy with sodium pertechnetate Tc $99 \mathrm{~m}$ showed mixed hypoechoic and hypoactive nodules in both thyroid lobes. Because of the suspicion of retrosternal goiter, scintigraphy with iodine 131 was performed, revealing that the mass took up radioiodine.

The diagnosis was expected to be thyroid malignancy with lung metastasis. Ultrasonographically guided fine-needle aspiration biopsy of the nodule in left thyroid gland with positive results on positron emission tomography was performed for definitive diagnosis. Pathologic examination

\footnotetext{
From the Departments of Thoracic Surgery, ${ }^{\mathrm{a}}$ Nuclear Medicine, ${ }^{\mathrm{b}}$ and Pathology, ${ }^{\mathrm{c}}$

Kocaeli University, The Faculty of Medicine, and the Department of Thoracic

Surgery, ${ }^{\mathrm{d}}$ İzmit State Hospital, Kocaeli, Turkey.

Received for publication Feb 4, 2008; accepted for publication March 2, 2008.

Address for reprints: Serife Tuba Liman, MD, Thoracic Surgery Department, Kocaeli

University, The Faculty of Medicine, Umuttepe Kampusu 41380, Kocaeli, Turkey

(E-mail: tubaliman@yahoo.com).

J Thorac Cardiovasc Surg 2009;138:231-3

$0022-5223 / \$ 36.00$

Copyright (c) 2009 by The American Association for Thoracic Surgery

doi:10.1016/j.jtcvs.2008.03.048
}

revealed no malignancy. Mediastinal mass was not confirmed histopathologically in preoperative period. The presumptive diagnosis at that point was therefore primary lung carcinoma in early stage and retrosternal goiter. Mediastinoscopy was not performed.

Through a posterolateral thoracotomy, it was observed that the tracheal bronchus had connection with only the apical segment of the right upper lobe, and air entry to the remaining segments of the right upper lobe came from the abnormal additional segment bronchus of the middle lobe bronchus (Figure 2). The parenchymal mass was located in the apical segment of the right upper lobe. Minor fissure was absent. Superior bilobectomy and mediastinal lymph node dissection were performed. An encapsulated mediastinal mass was dissected. The mass had no connection with the cervical thyroid gland. Histopathologic examiniation revealed poorly differentiated adenocarcinoma (T2NOM0) and colloidal ectopic thyroid tissue. The patient was discharged from the hospital on postoperative day 7 without any complications.

\section{DISCUSSION}

Ectopic thyroid tissue in thorax without any connection of cervical thyroid gland is seen very rarely. It is associated with diagnostic difficulties, potential for malignancy, and compression of mediastinal structures. ${ }^{2,3}$ Surgical excision of ectopic thyroid tissue is recommended for both diagnosis and treatment.

Ectopic thyroid tissues usually have their vascular supply from local mediastinal vessels, such as the internal thoracic and innominate arteries or the intrathoracic aorta, rather than the cervical blood supply. Surgical incision (sternotomy or thoracotomy) is determined by the location of the ectopic thyroid tissue.

Mediastinal thyroid tissue may be PET positive, even it is benign. This may cause some difficulties in diagnosis. In our case, the mediastinal mass was PET negative. PET-positive mediastinal thyroid tissue would be perplexing, necessitating extra investigations to differentiate it from bulky lymph nodes and mediastinal tumors. Ectopic goiters do not always take up radioiodine.

There was a PET-positive thyroid nodule in our patient. Thyroid incidentaloma is defined as abnormal fluorodeoxyglucose uptake in the thyroid gland found at PET scan. It is found at a frequency of $2.3 \%{ }^{4}$ In the Cohen study, 15 thyroid incidentalomas which were detected in PGT/CT scans of the patients with known primary malignancies were sampled and $47 \%$ of them were found malignant. ${ }^{4}$ 

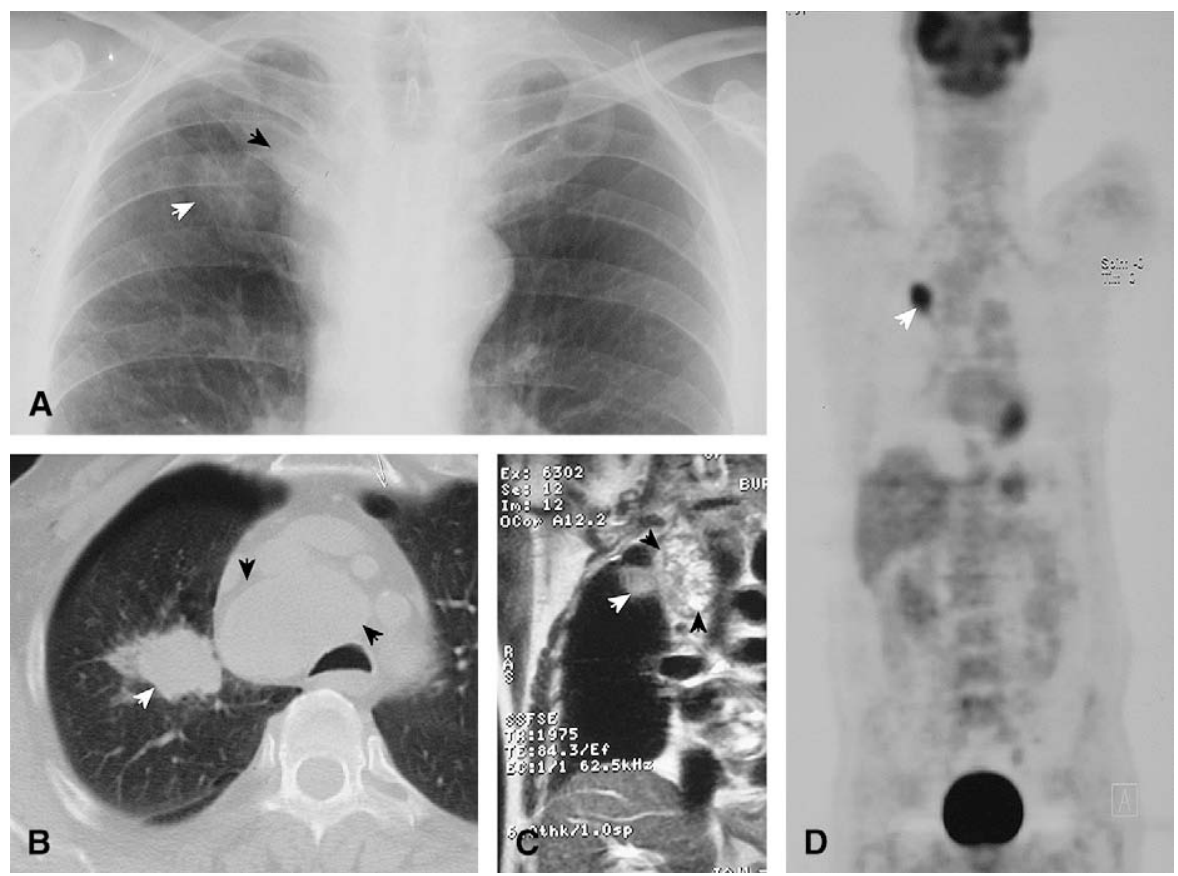

FIGURE 1. A, Posteroanterior chest radiography. B, Thoracic computed tomography. C, Thoracic magnetic resonance imaging. D, Positron emission tomographic image of the patient. White arrows show pulmonary mass in right upper lobe and black arrows show ectopic mediastinal thyroid. Latrogenic pneumothorx after transthoracic biopsy can be seen in CT section.

With such a high risk of malignancy, patients with new thyroid lesions found on PET scan should have a tissue diagnosis made.

Our patient had some bronchial abnormalities. He had bronchus suis anomaly, and it had connection with only the apical segment of the upper lobe. There was no orifice to the remainder of the upper lobe. There was, however, an abnormal middle lobe bronchus. Bronchi of the remaining segments of the upper lobe originated from the middle lobe bronchus. That was also an unusual abnormality.

In conclusion, ectopic thyroid tissue should be kept in mind in the differential diagnosis of mediastinal masses. Ectopic thyroid tissue may be associated with other tracheobronchial anomalies. If there are additional

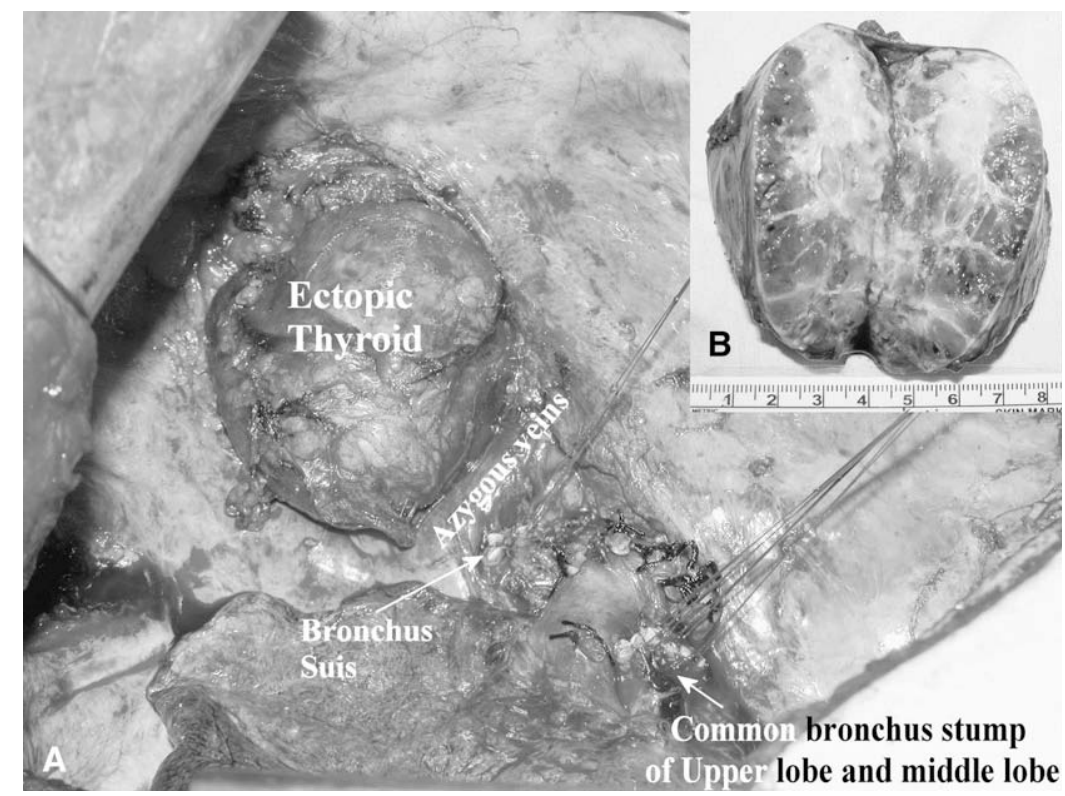

FIGURE 2. A, Operative view demonstrating bronchial abnormalities and mediastinal mass. B, Ectopic thyroid tissue. 
pathologies, such as lung nodules and lung carcinoma, there may be some diagnostic and therapeutic difficulties.

\section{References}

1. Gamblin TC, Jennings GR, Christie DB, Thompson WM, Dalton ML. Ectopic thyroid. Ann Thorac Surg. 2003;75:1952-3.
2. Kaya S, Tastepe I, Kaptanoglu M, Yuksel M, Topcu S, Cetin G. Management of intrathoracic goitre. Scand J Thorac Cardiovasc Surg. 1994;28: $85-9$

3. Kawakami M, Ito K, Yoshimura K, Tanaka H. A case of mediastinal goiter. Auris Nasus Larynx. 2004;31:183-7.

4. Cohen MS, Arslan N, Dehdashti F, Doherty GM, Lairmore TC, Brunt LM, et al. Risk of malignancy in thyroid incidentalomas identified by fluorodeoxyglucosepositron emission tomography. Surgery. 2001;130:941-6.

\title{
Potential for benefits of aprotinin use to outweigh risks in patients undergoing the Ross procedure
}

\author{
Stephen Arthur Barnett, MBBS, FRACS, Matthew Liava'a, MBBS, and Peter D. Skillington, MBBS, \\ FRACS, Melbourne, Australia
}

Recent reports ${ }^{1-3}$ of adverse events related to the use of aprotinin during complex cardiac surgery and the sudden suspension of the BART (Blood conservation using antifibrinolytics: A randomized trial in a cardiac surgery population) trial because of excess mortality in the treatment arm $^{4}$ highlight the risks of death, acute renal failure, and acute coronary thrombosis during the perioperative period after treatment with this drug. Our concern is that the very real benefits of the drug in terms of reductions in bleeding, need to return to the operating room, and rate of transfusion of blood and blood products ${ }^{2}$ may be overlooked as a result of the surgical community's admirable goal to "'first do no harm.' More specifically, we suspect that there may be a subgroup of younger patients undergoing complex cardiac surgical procedures who could derive many of the previously accepted benefits with a low risk of the recently highlighted adverse events attributed to the drug.

\section{CLINICAL SUMMARY}

Between October 1992 and November 2007, a total of 250 consecutive patients underwent the Ross procedure under the care of a single surgeon (P.D.S.). ${ }^{5}$ Aprotinin was administered routinely to all patients, according to the full Hammersmith protocol. ${ }^{6}$ Mean age was 39.5 years (range 15-62 years). Mean total bypass time was 195 minutes, and mean cumulative crossclamp time was 165 minutes.

Bleeding necessitating return to the operating room occurred in 7 patients $(2.8 \%)$. Transfusion of blood or blood products was necessary in 75 patients $(30 \%)$.

\footnotetext{
From the Royal Melbourne Hospital, Parkville, Melbourne, Victoria, Australia. Received for publication Jan 25, 2008; accepted for publication Feb 13, 2008.

Address for reprints: Stephen Arthur Barnett, MBBS, FRACS, The Royal Melbourne Hospital, Cardiothoracic Surgery, Grattan St, Parkville, Melbourne, Victoria 3050,

Australia (E-mail: stephenarthurbarnett@gmail.com).

J Thorac Cardiovasc Surg 2009;138:233-4

$0022-5223 / \$ 36.00$

Copyright (c) 2009 by The American Association for Thoracic Surgery

doi:10.1016/j.jtcvs.2008.02.066
}

With regard to adverse events often described as associated with the administration of aprotinin, there were no in-hospital deaths, and acute renal impairment (defined as a doubling of preoperative creatinine level) occurred in only 4 patients $(1.6 \%)$. No patients required hemofiltration. There were no acute thromboses of any coronary artery, although 2 patients $(0.8 \%)$ did require early revision (1 during the initial time in the operating room and 1 after return to the operating room) as a result of kinking of a coronary artery (this complication was encountered solely in the early period of the series and has since been universally prevented by a modification of technique).

\section{DISCUSSION}

It is our impression that young, fit patients undergoing complex procedures, such as the Ross procedure or adult congenital cardiac surgery, involving numerous suture lines and prolonged bypass times can benefit from the use of aprotinin. Further, in this select group of patients, who often have only a small burden of atherosclerotic coronary and renovascular disease, the possible thrombotic complications of aprotinin-namely acute coronary occlusion, acute renal failure, and subsequent in-hospital mortality — may be uncommon. The well-accepted benefits of reduced blood loss and the low rates of adverse events in this select group of patients may therefore tip the balance in favor of the ongoing use of this drug.

More work is needed. A randomized trial at our institution addressing whether withholding aprotinin from patients undergoing the Ross procedure would result in reduced inhospital mortality is impossible, however, because our starting death rate is $0 \%$. Similarly, withholding aprotinin in the hope of discerning a reduction in acute renal failure from our starting level of $1.6 \%$ would require many thousands of patients. 